\title{
The ORNL Plasma Fueling Program
}

M. J. Gouge, S. L. Milora, C. A. Foster, S. K. Combs, P. W. Fisher, C. C. Tsai, B. E. Argo, G. C. Barber, L. R. Baylor, D. T. Fehling, C. R. Foust, T. C. Jernigan, A. L. Qualls, D. E. Schechter, D. W. Simmons, C. W. Sohns and D. O. Sparks

\author{
Oak Ridge National Laboratory \\ P. O. Box 2009 \\ Oak Ridge, TN
}

$37831-8071$

\section{Introduction}

The Oak Ridge National Laboratory (ORNL) has been developing pellet injectors for over ten years. 1,2 These devices produce frozen hydrogen isotope pellets and then accelerate the projectiles to speeds in the $\mathrm{km} / \mathrm{s}$ range by either pneumatic (light-gas gun) or mechanical (centrifugal furce) techniques. A variety of designs have been developed, including single-shot (one-pellet) guns, multiple-shot (four- and eight-peliet) guns, machine guns (single- and multiple-barrel types), and centrifugal accelerators. These injectors have been used to inject hydrogen and deuterium pellets into plasmas on numerous tokamak experiments resulting in improved plasma performance. ORNL has recently provided pellet fueling systems for the Tokamak Fusion Test Reactor (TFTR), the Joint European Torus (JET), and the Tore Supra tokamak. The TFTR eight-shot pneumatic injector ${ }^{3}$ was installed in 1986 and has operated reliably since that lime. Record values of $n \tau$, the product of plasma density and energy confinement time have obtained in ohmic plasmas with this injector and, more recently, experiments with pellet fueling of ICRH-heated plasmas have produced encouraging results in high temperature plasma regimes. The JET three-barrel repeating pneumatic injector ${ }^{4-6}$ is the central part of a major collaboration between the United States and the European Community on plasma fueling and transport physics in the high-plasma-density regime. The injector was installed on JET in 1987 and has produced record values of $\mathrm{nT} \tau$ in high power density RF and neutral beam heated limiter plasmas while operating at high reliability. 6 ORNL has recently developed, tested and shipped to a centrifuge pellet injector ${ }^{7}$ to France for the extensive particle control experiments planned for the Tore Supra tokamak. The new injector will be featured in a collaboration with the Commissariat a l'Energie Atomique (CEA). The objective of this ORNL-CEA collaboration is to study long-pulse, reactor-relevant tokamak discharges with simultaneous plasma fueling and exhaust capabilities.

\section{Centrifuge Development}

For application on the Tore Supra tokamak, a centrifuge-type injector design was chosen; the design is based on an earlier mechanical device that provided the first quasi-steady-state fueling on the Loublet-III tokamak in 1984.17 The centrifuge injector is a mechanical device that uses centrifugal forces to 
accelerate pellets constrained to move in a track on a high-speed rotating arbor. The exit velocity of the pellet is about twice the tip velocity of the arbor. Two inherent advantages of this technique are steady-state capability and high pellet feed rates due to the inherent high rotational speeds of the accelerator. Thus, it can provide a flexible fuel source for long-pulse tokamaks.

The injector system (Fig 1.) is primarily divided into three subsystems:

(1) the vacuum containment " spin tank,"

(2) the pellet fabrication system or "Zamboni machine," and

(3) the high-speed mechanical accelerator.

Vacuum containment is provided by a 2-m-diam dome-shaped "spin tank," which houses the accelerator and supports the pellet fabrication system. The "Zamboni machine" device freezes a rim of solid hydrogen ice on a rotating disk, which is cooled with liquid helium. On command, a quantity of pellets up to the amount on a disk circumfrance can be punched. The voids formed on the rim after a pellet-punching sequence are replenished as the liquid-heliumcooled disk rotates and liquid-gas mixture from an adjacent extruder fills through the injection calipers. The accelerator is a 1.5 -m-diam snowshoeshaped graphite composite hoop that is coupled to a high-strength aluminum hub and is driven with an induction motor. A recessed area in the aluminum hub accepts the pellets from the "Zamboni" punch mechanism and guides them into a V-shaped groove in the composite hoop, where centrifugal forces accelerate the pellets to twice the peripheral speed of the rotor (tested at up to $127 \mathrm{~Hz}$ ). The pellets are shot through a guide tube injection line to the plasma.

The current performance of the new injector, which was shipped to Tore Supra in September 1989, is as follows:

(1)the capability of delivering up to $60-80$ hydrogen or deuterium pellets at a rate of up to 10 per second,

(2)variable pellet size (3-15 torr-L/pellet),

(3)pellet speeds in the range of $0.6-0.9 \mathrm{~km} / \mathrm{s}$, and

(4)pellet dispersion at the plasma surface within $30 \mathrm{~mm}$.

Figure 2 shows data from a sequence of 70 pellets at $600 \mathrm{~m} / \mathrm{s}$ at a repetition rate of $6 \mathrm{~Hz}$. Shown are the signals from a microwave cavity which is a measure of relative mass and the pressure in the target chamber at the end of the injection line. This injector will be installed on Tore Supra in the coming months and will be a part of the 1990 Tore Supra experimental program.

\section{Eight-shot Pneumatic Injectors for PBX,ATF and DIIID}

A simplified eight-shot pneumatic pellet injector design 8,9 has been developed at ORNL. Plasma fueling systems based on this design have been supplied to the Princeton Beta Experiment (PBX) in October 1988 and the Advanced Toroidal Facility (ATF) in May 1989. This injector design is based on the so-called "pipegun" concept, in which deuterium and hydrogen pellets are formed by direct condensation in the gun barrel, a segment of which is held below the hydrogen triple-point temperature by contact with a liquid-helium-cooled block. Pellet length is controlled both by regulating the gas fill pressure and by establishing temperature gradients along the barrel tube with auxiliary heating collars. This injector (Fig.3) features eight independent gun barrel 
assemblies mounted around the perimeter of a single cold block, each coupled to an ORNL-designed fast propellant valve. 10 The ORNL version of this valve develops full pressure within $300 \mathrm{~ms}$ and has operates routinely with a supply pressure of 70-100 bars with a modified version capable of pressures up to 300 bars. Thus, the injector is capable of injecting up to eight pellets of sizes ranging from 1 to $4 \mathrm{~mm}$ in arbitrarily programmable firing sequences at speeds up to approximately $1300 \mathrm{~m} / \mathrm{s}$. A similar system is being designed for the DIII-D tokamak at GA .

\section{High Velocity Development}

Higher pellet velocities ( $>2 \mathrm{~km} / \mathrm{s}$ ) are desirable for plasma fueling applications, because the faster pellets can penetrate more deeply into large, hot plasmas to deposit atoms of fuel directly in a greater fraction of plasma volume. Two techniques for achievirg higher speeds are being evaluated experimentally at ORNL.

\section{Two Stage Light Gas Gin Development}

Recently, ORNL began developing a two-stage light-gas gun 11,12 to accelerate pellets to high speeds. The basic single stage light gas gun is limited in performance by the sound speed of the room temperature propellant gas to about $2 \mathrm{~km} / \mathrm{s}$. To overcome this limitation, the two stage gun relies on a piston moving at high speeds $(100-350 \mathrm{~m} / \mathrm{s})$ in a cylinder to adiabatically compress the propellant gas ( $\mathrm{He}$ or $\mathrm{H}$ ) to high pressure and temperature in a chamber located at the gun breech. Ignoring the mass loss down the gun barrel and heat transfer to the walls of the pump tube, the pressure and temperature in front of the piston are related to the length of the pump tube and the distance $x$ traversed by the piston by the adiabatic compression formulae as:

$$
\frac{P}{P_{0}}=\left[\frac{L}{(L-x)}\right]^{\gamma} \text { and } \frac{T}{T_{0}}=\left[\frac{L}{(L-x)}\right]^{\gamma-1}
$$

According to this result. pressures much higher than the first stage reservoir pressure and high temperatures will be generated as the distance $x$ approaches L. Because of its higher temperature capability, the two stage gun can be designed to more closely approximate the ideal constant base pressure gun which as its name implies provides a uniform acceleration along the gun barrel. The large force imbalance is made possible by the inertia of the piston. By carefully choosing the operating conditions, the piston can be made to approach the cylinder head to within a few $\mathrm{mm}$ or less before it stops and reverses direction.

In the initial configuration of the two-stage device (Fig. 4), a 2.2-L volume (pressure $<120$ bar) provides the gas to accelerate a 25.4-mm-diam plastic piston in a 1-m-long pump tube; a burst disk or a fast valve initiates the acceleration process in the first stage. As the piston travels the length of the pump tube, the downstream gas (initially at $<1$ bar) is compressed (to pressures $>2500$ bar) and thus is driven to high temperatures (approximately 5,000$10,000-K)$. This provides the driving force for acceleration of a $4-\mathrm{mm}$ pellet in a 1-m-long gun barrel. In tests that used helium gas as the driver in both 
stages, 35-mg plastic pellets have been accelerated to speeds as high as 4.5 $\mathrm{km} / \mathrm{s}$. More recently, bare deuterium pellets formed in a pipe gun geometry have been accelerated to speeds near $2900 \mathrm{~m} / \mathrm{s}$ using a specially designed pneumatic valve between the first and second stages. Theoretical modeling 12 of these experiments with a one-dimensional Lagrangian hydrodynamics code has identified gas friction in the pump tube and small diameter barrel to be the dominate loss mechanism. The use of sabots to encase and protect the cryogenic pellets from the high peak pressures will be required to realize speeds above about $3 \mathrm{~km} / \mathrm{s} .{ }^{13}$ The speeds of bare hydrogenic pellets have also been limited by a progressive reduction in the pellet diameter thought to be due to erosion by the gun barrel wall which becomes important at speeds of 2 $\mathrm{km} / \mathrm{s}$ and above. 13,14 Speeds as high as $3.8 \mathrm{~km} / \mathrm{s}$ have been achieved by encasing the pellet in a capsule known as a sabot. 13 With sabots, the pellet can withstand the higher acceleration rates imposed by the two stage gun and is protected from the effects of erosion. Sabots which separate from the pellet after it exits the muzzle are being developed at ORNL and in Europe. This technology at ORNL is being developed for long pulse to continuous fueling of such devices as CIT and ITER. Piston lifetimes have exceeded 50 experimental shots and recently the 2 stage light gas gun has been operated in a multishot mode.

\section{Electron Beam Rocket Accelerator}

A second metiod under development at ORNL for attaining higher speeds is based on an electron-team-driven rocket. $7,15,16$ The method uses intense electron beam heating for ablation of a hydrogen propellant "ice stick" to accomplish rocket-like acceleration of deuterium and/or tritium pellets (possibly to speeds of $10 \mathrm{~km} / \mathrm{s}$ or greater. Unlike other pellet injection concepts already discussed, the acceleration increases as the mass of the system ( propellant plus payload) decreases. The final velocity is given in terms of the initial and final masses $M_{0}$ and $M_{f}$ by the well known rocket equation as

$$
\mathrm{U}_{\mathrm{f}}=\mathrm{U}_{\mathrm{ex}} \ln \left(\mathrm{M}_{\mathrm{o}} / \mathrm{M}_{\mathrm{f}}\right)
$$

For practical mass ratios in the range of 3 to 10 , exhaust gas velocities of 5 $\mathrm{km} / \mathrm{s}$ and above will be required to achieve pellet speeds in the $10 \mathrm{~km} / \mathrm{s}$ range. Figure 5 shows a system under development at ORNL that consists of a pipegun-type pellet fabricator, an electron gun, an accelerating column (including guide rails), and a set of solenoid magnets for electron beam compression and confinement. Models suggest that the axial magnets can compress electron beams to achieve current densities above $100 \mathrm{~A} / \mathrm{cm}^{\wedge} 2$ and can contain the beam along the guide rails in the acceleration column. The pellet fabrication and loading device has been constructed and operated reliably to produce long hydrogen pellets, $4 \mathrm{~mm}$ in diameter by $12 \mathrm{~mm}$ long. The electron-gun has been tested up to $30 \mathrm{keV}$ and 25 amps and coils for the axial magnets have been operated to produce a pulsed magnetic field above $1 \mathrm{~T}$ for $0.2 \mathrm{~s}$. Initial pellet acceleration experiments were recently performed with 4 $\mathrm{mm}$ diameter $\times 12 \mathrm{~mm}$ long hydrogen pellets in a $0.6 \mathrm{~m}$ acceleration path. Speed increments up to $300 \mathrm{~m} / \mathrm{s}$ after an electron beam impulse have been measured and the speed increment increases with electron beam power. 
The properties of tritium, especially its radioactive decay, are quite different Irom those of the other hydrogen isotopes. Decay heating, the production of ${ }^{3} \mathrm{He}$ and its effect on the physical propertic: of solid tritium, the need for tritium-compatible materials of construction and the use of double containment to prevent accidental release are all problems unique to tritium. In particular, the decay heat generates internal temperature gradients in the solid which could lead to a softening of the core and and a limitation on the maximum feasible pellet size. Because of these differences, it is desirable to demonstrate the production and acceleration of tritium pellets.A pipe gun has been developed for the tritium proof-of-principle (TPOP) experiment.17-19 This injector is based on the pneumatic pipe-gun concept, in which pellets are formed in situ in the barrel and accelerated with high-pressure gas. This injector is ideal for tritium service because there are no moving parts inside the gun and because no excess tritium is required in the pellet production process. Removal of $3 \mathrm{He}$ from tritium to prevent blocking of the cryopumping action by the noncondensible gas is accomplished with a cryogenic separator. The tritium is purified by circulating the fuel charge through the separator which freezes only the hydrogenic isotopes and leaves the noncondensible ${ }^{3}$ He to be removed from the loop by a mechanical vacuum pump. The experiment has been installed and operated with tritium in the Tritium Systems Test Assembly at Los Alamos National Laboratory. The TPOP experiment has completed the initial phase of experiments. The first tests of pellet fabrication and acceleration have recently been performed on pellets composed of tritium, equilibrium DT $\left(\mathrm{T}_{2}=\mathrm{D}_{2}=25 \%, \mathrm{DT}=50 \%\right)$ and various $\mathrm{DT}$ mixtures. Experiments have shown that the presence of ${ }^{3} \mathrm{He}$ at levels above $0.005 \%$ prevents pellet formation by blocking the condensation of tritium in the pipe gun freezing cell. Otherwise, no limitations to the fabrication and acceleration of $4 \mathrm{~mm}$ tritium pellets have yet been discovered at typical single stage gas gun acceleration levels yielding speeds of $1400 \mathrm{~m} / \mathrm{s}$. Figure 6 shows velocities obtained for both deuterium and tritium pellets for hydrogen propellant supply pressures up to 100 bar. The reduction in velocity for tritium is a result of the larger mass per unit area of the tritium pellets.

1. S.L. Milora, J. Fusion Energy 1 (1981) 15.

2. S. L. Milora. "Review of Hydrogen Pellet Injection Technology for Plasma Fueling Applications," J. Vac. Sci. Technol. A7(1989)925.

3. S.K. Combs et al., Rev. Sci. Instrum. 58 (1987) 1195.

4. S.L. Milora et al., in: Proceedings of the 12th Symposium on Fusion Engineering, Monterey, California, October 1987, Vol. 2, p. 784.

5. S.K. Combs et al., J. Vac. Sci. Technol. A 6(3) (1988) 1901.

6. S. K. Combs, T. C. Jemigan, L. R. Baylor et. al., "Performance of Pneumatic Hydrogen - Pellet Injection System on the Joint European Torus," Rev. Sci. Instrum. 60(1989) 2697. 
7. S.K. Combs et al., in: Fusion Technology 1988 (Proc.15th Symp.

Utrecht, The Netherlands, Sept. is-23, 1988), Vol. 1, p. 709.

8.D. D. Schuresko, M. J. Ccle, P. W. Fisher et. al., "Simplified Eight-Shot Pneumatic Pellet Injector for Plasma Fueling Applications on the Princeton Beta Experiment and on the Advanced Toroidal Facility," J. Vac. Sci. Technol. A7(1989)949

9.A. L. Qualls et al., these proceedings.

10. S.L. Milora et al., Rev. Sci. Instrum. 57 (1986) 2356.

11. S. K. Combs, C. R. Foust, M. J. Gouge and S. L. Milora, "Development of a TwoStage Light Gas Gun to Accelerate Hydrogen Pellets to High Speeds for Plasma Fueling Applications," J. Vac. Sci. Technol. A7(1989)963.

12. M. J. Gouge, S. K. Combs, P. W. Fisher and S. L. Milora, "Design Considerations for Single Stage and Two Stage Pneumatic Pellet Injectors," Rev. Sci. Instrum. 60(1989) 570.

13. K. Sonneberg et al., in: Proceedings of the 12th Symposium on Fusion Engineering, Monterey, California, October 1987, Vol. 2, p. 1207.

14. A. Reggiori, G. Riva, G. Daminelli, A. Frattolillo, L. Martinis and F. Scaramuzzi, J. Vac. Sci. Technol. A5,959 (1989).

15. C.A. Foster et al., Bull. Am. Phys. Soc. 31 (1986) 1599.

16. C. C. Tsai et. al., these proceedings

17. P.W. Fisher et al., Fusion Technol. 14977 (1988)

18. P. W. Fisher, M. L. Bauer, L. R. Baylor et. al., "Tritium Pellet Injector Results," J. Vac. Sci. Technol. A7(1989)938.

19. P. W. Fisher et. al.,these proceedings.

\section{List of Figures}

1. Photo $8135-89$

2. Data from Camac given to Reports office for drawing.

3. Photo $8550-88$

4. ORNL DWG 88-3279 


\section{ORNL DWG 88-3555 FED (latest version) \\ 6. ORNL DWG 88C-3396A FED}

Figure Captions

1. The Tore Supra Centrifuge Pellet Injector 2. Chamber Pressure and Microwave Cavity Signals from 70 pellet
sequence

3. The PBX Pellet Injector Gun Internals

4. ORNL 2-Stage Light Gas Gun Schemetic

5. Electron Beam Pellet Accelerator Test Facility

6. Pellet Velocity Data from TPO? Experiment

\section{DISCLAIMER}

This report was prepared as an account of work sponsored by an agency of the United States Government. Neither the United States Government nor any agency thereof, nor any of their employees, makes any warranty, express or implied, or assumes any legal liability or responsibility for the accuracy, completeness, or usefulness of any information, apparatus, product, or process disclosed, or represents that its use would not infringe privately owned rights. Reference herein to any specific commercial product, process, or service by trade name, trademark, manufacturer, or otherwise does not necessarily constitute or imply its endorsement, recommendation, or favoring by the United States Government or any agency thereof. The views and opinions of authors expressed herein do not necessarily state or reflect those of the United States Government or any agency thereor. 